\title{
Abducens Nerve Palsy and Ipsilateral Incomplete Horner Syndrome: A Significant Sign of Locating the Lesion in the Posterior Cavernous Sinus
}

\author{
Teruyuki Kurihara \\ Key words: abducens nerve palsy, Horner syndrome, posterior cavernous sinus, sympathetic nerve fibers
}

(DOI: 10.2169/internalmedicine.45.0163)

It is a rare combination of neurological manifestations to have abducens nerve palsy and ipsilateral incomplete Horner syndrome. When a patient has right abducens nerve palsy he will complain of double vision and the image becomes more doubled when he looks to the right since his right eye cannot abduct. In addition he has right postganglionic Horner syndrome which causes mild right ptosis, and his right pupil is smaller than the left pupil. He does not have any sweating abnormality of his right face, since his Horner syndrome is postganglionic. Complete Horner syndrome includes anhidrosis of the face (1). Incomplete Horner syndrome includes ptosis, miosis without anhidrosis.

The abducens nerve is the 6th cranial nerve traveling from the pons to the lateral rectus muscle of the eye following a long and tortuous course passing over the hard temporal bone and this cranial nerve is vulnerable to trauma, pressure, inflammation, ischemia, diabetes mellitus (diabetic ophthalmoplegia). This nerve shows paresis as a false localizing sign in increased intracranial pressure.

Horner syndrome can occur in any one of the interruptions when the sympathetic nerve travels (1) from the hypothalamus descending through the ipsilateral sympathetic pathways in the brain stem to the spinal cord, (2) from the spinal cord to the superior cervical ganglion (preganglionic fiber), and (3) from the ganglion to the orbit (postganglionic fiber) accompanying the internal carotid artery $(1,2)$. Common lacations of the lesion (2) causing Horner syndrome include the lateral hypothalamic area (complication after thalamotomy for dyskinesia), the lateral medulla (Wallenberg syndrome), the spinal cord (syringomyelia), the lung apex (Pancoast tumor), brachial plexus palsy (Klumpke's palsy), the neck (traumatic wound, cervical adenopathy), carotid artery (thrombosis), cavernous sinus(carotid aneurysm, carotidcavernous fistula, tumor, trauma, inflammation), the orbit (retroorbital tumor), the ciliary ganglion (destructive lesion), and even cluster headache (2) can cause Horner syndrome.

Tsuda et al (3) originally presented a case of abducens nerve palsy and Horner syndrome due to metastatic parotid carcimoma to the cavernous sinus in 2005 , and the authors accumulated 9 cases with helps of neuro-ophthalmologists and reported them in 2006 (4). The ages of 9 patients ranged from 28 to 63 years, 6 male and 3 female cases. Five patients with extracavernous sinus lesions had headache, and four patients with intracavernous sinus lesions did not have a headache. Their Horner syndrome included mild ptosis and miosis without anhidrosis. After appropriate treatment, abducens nerve palsy improved in 5 out of 9 cases, but Horner syndrome persisted in all 9 cases. The complete Horner syndrome includes ptosis, miosis, and ipsilateral anhidrosis of the face; these symptoms occur in the case of preganglionic sympathetic injury. The sympathetic nerve fibers governing facial sweating travel along the external carotid artery after leaving the superior cervical ganglion (5). That is the reason why postganglionic injury does not cause anhidrosis.

The etiology of abducens nerve palsy and Horner syndrome includes metastatic tumor (from parotid carcinoma, stomach cancer, small cell carcimoma of the lung, breast cancer), epipharynx carcinoma, megingioma, extension of chordoma, intracavernous internal carotid artery aneurysm, carotid-cavernous fistula, head trauma, cryptococcal meningitis, herpes zoster ophthalmicus, sphenoidal sinus cyst).

Neither abducens nerve palsy, nor Horner syndrome promptly indicates the location of the lesion; however, when both are present it is of significant value to determine the site of the lesion. If we review the anatomical course of the ocular sympathetic nerve, postganglionic sympathetic fibers travel over the wall of the internal carotid artery and then ascend to the brain and in the cavernous portion the sympathetic fibers leave the internal carotid artery and accompany 
the abducens nerve for only a few millimeters in the posterior portion of the cavernous sinus, and then leave the abducens nerve to join the first division of the trigeminal nerve (5).

The combination of abducens nerve palsy and ipsilateral postganglionic Horner syndrome has been reported since 1981 by Abad et al $(6,7)$ and there are 19 cases in the English language literature $(6,8-14)$. Another 8 cases were added by Tsuda et al in 2006 (4), since one of the nine cases had been already reported in 2005 (3). Although the present clinical manifestations are rare, abducens nerve palsy and ipsilateral Horner syndrome has a significant value to localize the neurological lesion since abducens nerve and sympathetic fibers meet for only a few millimeters in the posterior portion of the cavernous sinus. The photograph in the article of Tsuda et al clearly shows the precise neuroanatomy of this narrow area $(3,4)$.

\section{References}

1. Haerer AF. Sympathetic innervation. in: DeJong's The Neurologic Examination. Fifth ed. J.B. Lippincott, Philadelphia, New York, London, Hagerstown, 1997: 129-133.

2. Huertus $J$ (revised). Localization of lesions of cervical and upper thoracic segments; autonomic disturbances. in: Bing's Local diagnosis in neurological diseases. Fifteenth ed. Haymaker W Ed, The C. V. Mosby, St. Louis, 1969: 101-103.

3. Tsuda H, Ishikawa H, Asayama K, Saito T, Endo S, Mizutani T. Abducens nerve palsy and Horner syndrome due to metastatic tumor in the cavernous sinus. Intern Med 44: 644-646, 2005.

4. Tsuda H, Ishikawa H, Kishiro M, Koga N, Kashima Y. Abducens nerve palsy and postganglionic Horner syndrome with or without severe headache. Intern Med 45: 851-855, 2006.

5. Fujisawa H, Marukawa K, Kida S, Hasegawa M, Yamashita J, Matsui O. Abducens nerve palsy and ipsilateral Horner syndrome: a predicting sign of intracranial carotid injury in a head trauma patient. J Trauma 50: 554-556, 2001.

6. Abad JM, Alvarez F, Blazquez MG. An unrecognized neurological syndrome: sixth-nerve palsy and Horner's syndrome due to traumatic intracavernous carotid aneurysm. Surg Neurol 16: 140-144, 1981.

7. Abad Rico JM, Alvarez Ruiz F, Munoz J, Perez Higueras A, Garia
Blazquez M. A little recognized neurological syndrome: paralysis of the 6th pair and Bernard-Horner syndrome caused by traumatic intracavernous lesions. Rev Clin Esp 165: 135-140, 1982.

8. Gutman I, Levartovski S, Goldhammer Y, Tadmor R, Findler G. Sixth nerve palsy and unilateral Horner's syndrome. Ophthalmology 93: 913-916, 1986.

9. Hartmann B, Kremer I, Gutman I, Krakowski D, Kam J. Cavernous sinus infection manifested by Horner's syndrome and ipsilateral sixth nerve palsy. J Clin Neuroophthalmol 7: 223-226, 1987.

10. Striph GG, Burde RM. Abducens nerve palsy and Horner's syndrome revisited. J Clin Neuroophthalmol 8: 13-17, 1988.

11. Tola-Arribas MA, Zarco-Tejada JM, Marco-Llorente J. Horner's syndrome secondary to ophthalmic herpes zoster. Rev Neurol 25: 1922-1924, 1997 (in Spanish).

12. Silva MN, Saeki N, Hirai S, Yamamura A. Unusual cranial nerve palsy caused by cavernous sinus aneurysms. Clinical and anatomical considerations reviewed. Surg Neurol 52: 143-148, 1999.

13. Parkinson D. Horner's syndrome and sixth nerve palsy. Surg Neurol 53: 94-95, 2000.

14. Pandey PK, Garg D, Bhatia A, Jain V. Horner's syndrome and sixth nerve palsy due to herpes zoster ophthalmicus arteritis. Eye 19: 224-226, 2005.

(C) 2006 The Japanese Society of Internal Medicine http://www.naika.or.jp/imindex.html 